\title{
Neuron-specific enolase as a novel biomarker reflecting tuberculosis activity and treatment response
}

\author{
Sung-Jin Nam ${ }^{1, *}$, Jee-Yeong Jeong, ${ }^{2,3}$, , Tae-Won Jang ${ }^{4}$, Mann-Hong Jung ${ }^{4}$, Bong-Kwon Chun ${ }^{5}$, \\ Hee-Jae $\mathrm{Cha}^{6}$, and Chul-Ho Oak ${ }^{4}$
}

\begin{abstract}
${ }^{1}$ Department of Internal Medicine, Gyeongsang National University Changwon Hospital, Changwon; ${ }^{2}$ Department of Biochemistry, ${ }^{3}$ Cancer Research Institute, Departments of ${ }^{4}$ Internal Medicine, ${ }^{5}$ Pathology, and ${ }^{6}$ Parasitology and Genetics, Kosin University College of Medicine, Busan, Korea
\end{abstract}

Received: December 23, 2015

Revised : March 12, 2016

Accepted: March 21, 2016

\section{Correspondence to}

Chul-Ho Oak, M.D.

Department of Internal Medicine, Kosin University College of

Medicine, 262 Gamcheon-ro,

Seo-gu, Busan 49267, Korea

Tel: +82-51-990-6104

Fax: +82-51-990-3010

E-mail: oaks7o@hanmail.net

*These authors contributed equally to this work.
Background/Aims: It is not clear which tests are indicative of the activity and severity of tuberculosis (TB). This study aimed to investigate the predictive value of neuron-specific enolase (NSE) and to determine the origin of NSE in TB patients. Methods: A single-center retrospective analysis was conducted on newly diagnosed TB patients between January and December 2010. Patients were categorized into one of two disease groups (focal segmental or extensive) based on chest X-ray. Pre- and post-treatment NSE concentrations were evaluated. To determine the origin of serum NSE concentration, NSE staining was compared with macrophage-specific CD68 staining in lung tissues and with a tissue microarray using immunohistochemistry and immunofluorescence.

Results: A total of 60 newly diagnosed TB patients were analyzed. In TB patients, NSE serum concentration was significantly increased and NSE level decreased after treatment $(p<0.001)$. In proportion to serum high-sensitivity C-reactive protein concentration, the mean serum concentration of NSE in the extensive group $(25.12 \mathrm{ng} / \mathrm{mL}$ ) was significantly higher than that in the focal segmental group $(20.23 \mathrm{ng} / \mathrm{mL}, \mathrm{p}=0.04)$. Immunohistochemical staining revealed a large number of macrophages that stained positively for both NSE and CD68 in TB tissues. In addition, NSE signals mostly co-localized with CD68 signals in the tissue microarray of TB patients.

Conclusions: Our results suggest that NSE may be a practical parameter that can be used to monitor TB activity and treatment response. Elevated serum NSE level originates, at least in part, from macrophages in granulomatous lesions.

Keywords: Phosphopyruvate hydratase; C-reactive protein; Diagnosis; Response; Tuberculosis, pulmonary

\section{INTRODUCTION}

Pulmonary tuberculosis (T'B) is a chronic disease caused by the bacillus Mycobacterium tuberculosis and spreads from person to person through airborne transmission. TB remains a leading cause of morbidity and mortali- ty in many countries. Current anti-TB treatments have several problems, including the development of multidrug resistance and human immunodeficiency virus (HIV) coinfection [1,2]. TB usually affects the lungs but can also affect other parts of the body, such as the brain, intestines, kidneys, and/or the spine [3]. In cases of pul- 
monary TB, symptoms include chronic cough, chest pain, hemoptysis, weakness or fatigue, weight loss, fever, and night sweats [4]. Determination of TB activity is as important as early diagnosis for optimal treatment. Chest radiography, sputum acid-fast staining, and mycobacterial culture are the common clinical methods used to evaluate the therapeutic response of pulmonary TB [5]. Novel diagnostic tools, including serological tests and interferon- $\gamma$ release assays, have been developed for the rapid and accurate diagnosis of latent TB $[6,7]$. However, it is still uncertain whether these test results reflect disease activity and/or therapeutic response [8].

Neuron-specific enolase (NSE; phosphopyruvate hydratase) is the neuronal form of the glycolytic enzyme enolase, which is found in brain tissue extracts, neuroendocrine cells, and neuroendocrine tumors including small cell lung cancer (SCLC) [9,10]. Inoue et al. [11] have reported significantly higher NSE level in cerebrospinal fluid during bacterial meningitis. In addition, non-malignant inflammatory lung disorders have been reported to be associated with abnormal NSE serum concentration [12,13]. In a study from Collazos et al. [12], 27.3\% of all patients with active pulmonary TB had increased NSE concentration compared with $11.1 \%$ of all patients with overall benign pulmonary disease. Recently, Stammet et al. [14] have reported that serial NSE values are strong predictors of poor outcome after out-of-hospital cardiac arrest.

To date, there have been no reports on the relationship between activity of pulmonary TB and serum NSE concentration or on NSE concentration changes depending on treatment and extent of lung infiltration. It is uncertain whether NSE is an acute phase reactant, such as high-sensitivity C-reactive protein (hs-CRP), an acute-phase protein and nonspecific marker of bacterial pneumonia, or if NSE is a potential biomarker of active and latent TB [15]. Honda et al. [16] have reported that NSE is released from macrophages stimulated with interferon- $\gamma$ in hemophagocytic lymphohistiocytosis (HLH) and have suggested that serum NSE level is a useful marker for predicting the disease progression of HLH. Based on the pathogenetic similarity between HLH and TB, we postulated that macrophages stimulated by interferon- $\gamma$ within the granuloma tissue also produce NSE in TB, and the resulting elevated serum NSE concentration can serve as a useful biomarker of disease activity of TB. Macrophages have been shown to play a key role in the formation of granulomas in TB infection [17-19]. Kang et al. [17] have reported that macrophages produce VEGF, HIF- $1 \alpha$, and thymosin $\beta 4$, suggesting that these species promote the development of granuloma.

In this study, we aimed to measure serum NSE and hsCRP concentrations to establish the clinical correlations between NSE and hs-CRP serum concentrations with extent of inflammation in patients with active TB and to establish the origin of NSE in granulomatous lesions in patients with tuberculoma.

\section{METHODS}

\section{Patients and study design}

Sixty patients diagnosed with active pulmonary TB who completed treatment using first-line anti-TB agents at Kosin University Gospel Hospital from January to December 2010 and 30 age- and sex-matched healthy controls were enrolled in this retrospective study. The diagnosis of active pulmonary TB was based on a positive respiratory specimen culture and/or a positive result in a TB-polymerase chain reaction assay. Treatment regimens for TB have an initial phase of 2 months, followed by a continuation phase of either 4 or 7 months (total of 6 or 9). For initial treatment of TB, patients were treated with a 4-drug regimen including isoniazid, rifampin, ethambutol, and pyrazinamide. After 2 months, pyrazinamide was discontinued.

Sputum smear for acid-fast bacilli (AFB), mycobacterial culture for $M$. tuberculosis, and chest radiography were examined every 1 or 2 months during treatment. For patients who did not expectorate sputum, bronchoscopy was conducted for mycobacterial culture of $M$. tuberculosis. Patients with malignancy or recurrent TB infection were excluded based on medical history evaluation.

The objective of this study was to compare the serum NSE concentrations of TB patients with those of ageand sex-matched healthy controls. The study further aimed to determine whether NSE concentration changes after anti-TB treatment and whether NSE concentration could be used to monitor TB activity and treatment response. Patients underwent blood sampling to determine serum NSE concentration before and after com- 
Table 1. The baseline clinical characteristics of the patients

\begin{tabular}{|c|c|c|c|}
\hline Characteristic & Patient & Healthy control & $p$ value \\
\hline Sex, male:female & $25: 35$ & $12: 18$ & \\
\hline Age, yr & $64.2(18-78)$ & $60.8(20-72)$ & \\
\hline \multicolumn{4}{|l|}{ Active tuberculosis $(\mathrm{n}=60)$} \\
\hline Extensive infiltration & 25 & & \\
\hline Focal segmental infiltration & 35 & & \\
\hline Serum NSE concentrations, ng/mL & $24.59(15.2-40.00)$ & $5.05(2.00-8.00)$ & $<0.05$ \\
\hline Serum hs-CRP concentrations, mg/L & $4.24(0.61-8.64)$ & $0.8(0.1-4 \cdot 3)$ & $<0.001$ \\
\hline
\end{tabular}

Values are presented as mean (range).

NSE, neuron-specific enolase; hs-CRP, high-sensitivity C-reactive protein.

pletion of anti-TB treatment. The group of patients with TB was composed of 25 men and 35 women with a mean age of 64.2 years (range, 18 to 78 ). All patients underwent clinical, laboratory, and radiologic evaluations and were categorized into either a focal segmental infiltration group ( 35 patients total, including 10 tuberculoma, 15 segmental infiltration, and 10 small nodular infiltration patients) or an extensive infiltration group (25 patients, including five miliary and 20 lobar infiltration patients) (Table 1). Both serum and biopsy samples were obtained from the Department of Pathology at Kosin University College of Medicine. This study was approved by the Institutional Review Board and Ethics Committee of Kosin University Gospel Hospital (KUGH IRB No. 13-085) and was conducted in accordance with the Declaration of Helsinki.

\section{Measurement of serum NSE and hs-CRP}

Serum concentrations of NSE and hs-CRP were determined by radioimmunoassay. Normal serum NSE and hs-CRP concentrations were set at less than $15 \mathrm{ng} / \mathrm{mL}$ and $3 \mathrm{mg} / \mathrm{L}$, respectively. Hemolytic specimens were excluded because blood cell lysis influences the measured concentrations of both biomarkers.

\section{Immunohistochemical staining of granulomatous lesions}

Immunohistochemical staining of lung biopsy specimens of 10 TB-infected patients was performed using antibodies against NSE and a human macrophage marker, CD68. Specimens were obtained from the Department of Pathology at Kosin University College of Medicine. Immunohistochemistry was performed on
4- $\mu$ m-thick sections of paraffin blocks using the BondMax Autostainer (Leica Microsystems, Bannockburn, IL, USA). Tissue sections were deparaffinized and rehydrated following standard procedures. Heat-induced antigen retrieval was carried out, and sections were incubated with primary antibodies for 32 minutes at $37^{\circ} \mathrm{C}$ at a dilution of 1:3 polyclonal rabbit anti-NSE and 1:6,000 anti-CD68 antibodies (Dako, Carpinteria, CA, USA). Primary antibody binding was detected using the Bond Polymer Refine Detection kit (Leica Microsystems) according to the manufacturer's instructions.

\section{Immunofluorescence analysis}

Tissue microarrays consisting of 100 tissue cores $(80$ TB-infected, eight lung cancer, and 12 normal) were purchased from US Biomax (Rockville, MD, USA). No clinical information except age, sex, and pathological status of each patient was available for the tissues in these arrays. Patient characteristics and NSE and CD68 staining intensities in the tissue microarray are described in Supplementary Table 1. For immunofluorescence analysis, tissue slides were deparaffinized and hydrated. For antigen retrieval, slides were immersed in citrate buffer (0.01 M, pH 6.0) and heated twice in a microwave (700 W or higher) for 5 minutes each. Slides were permeabilized by incubation in phosphate-buffered saline (PBS) containing $0.1 \%$ Triton $\mathrm{X}-100$ for 5 minutes and then incubated with $10 \%$ normal serum in PBS for 1 hour to block nonspecific antibody binding. Slides were then incubated with a mixture of antibody to NSE (1:200 dilution; Dako) and CD68 (1:100 dilution; Dako) overnight at $4{ }^{\circ} \mathrm{C}$. After primary antibody incubation, slides were washed three times in PBS each for 5 minutes and incubated 
with secondary antibodies (Alexa Fluor 546-conjugated anti-mouse antibody and Alexa Fluor 488-conjugated anti-rabbit antibody, Invitrogen, Carlsbad, CA, USA) for 1 hour. Specimen epifluorescence was examined using confocal laser-scanning microscopy. The specificity of each antibody was confirmed by staining with rabbit or mouse polyclonal immunoglobulin G. A well-trained pathologist read the slides and scored the signals of NSE and CD68 blinded to clinical information.

\section{Statistical analysis}

Statistical analyses were conducted using SPSS version 20.0 (IBM Co., Armonk, NY, USA). Patient characteristics were summarized descriptively. A two-tailed $p$ value less than 0.05 was considered statistically significant. Correlation analyses were performed to generate the Pearson correlation coefficients to determine the relationships between variables. Paired $t$ tests were conducted to compare the differences in NSE and hs-CRP concentrations before and after anti-T'B treatment.

\section{RESULTS}

\section{NSE and hs-CRP concentrations in patients with tuberculosis}

NSE serum concentration was significantly higher in pulmonary TB patients (mean [range], $24.59 \mathrm{ng} / \mathrm{mL}[15.20$ to 40.00$])$ than in matched healthy controls $(5.05 \mathrm{ng} / \mathrm{mL}$ [2.00 to 8.00]; $p<0.05$ ). In addition, hs-CRP was also significantly higher in pulmonary TB patients $(4.24 \mathrm{mg} / \mathrm{L}$ [0.61 to 8.64]) than in controls (0.80 mg/L [0.10 to 4.30]; $p<0.001$ ) (Table 1). The mean serum concentrations of NSE and hs-CRP in the extensive type group (25.12 ng/ $\mathrm{mL}$ and $4.12 \mathrm{mg} / \mathrm{L}$, respectively) were significantly higher than those in the focal segmental type group (20.23 $\mathrm{ng} / \mathrm{mL}$ and $2.12 \mathrm{mg} / \mathrm{L}$, respectively; $p=0.04$ ).

\section{Correlation between NSE and hs-CRP before and after treatment}

Serum NSE concentration positively correlated with hsCRP concentration in active pulmonary TB patients $(p=$ $0.002, r^{2}=0.741$ ) (Fig. 1). After anti-TB therapy (i.e., at 6 or 9 months after the start of anti-TB treatment), the concentrations of both biomarkers were considerably lower than before anti-TB therapy; NSE decreased from 24.59

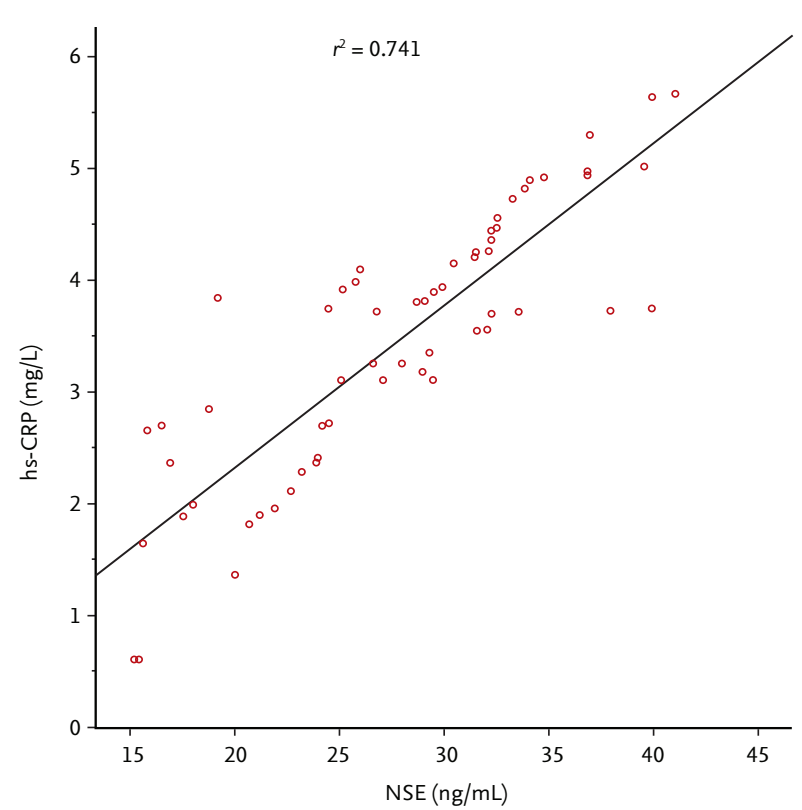

Figure 1. Correlation between serum neuron-specific enolase (NSE) and high-sensitivity C-reactive protein (hs-CRP) concentrations at the time of diagnosis in patients with active pulmonary tuberculosis.

(15.20 to 40.00 ) to 7.23 (2.2 to 11.4$) \mathrm{ng} / \mathrm{mL}$ and hs-CRP from 4.24 (o.61 to 8.64 ) to 1.62 (o.40 to 3.82 ) mg/L (Fig. 2).

\section{Detection of NSE and CD68 by immunohistochem- ical staining}

Immunohistochemical staining revealed a large number of both NSE- (green arrows) and CD68-positive (red arrows) macrophages around caseating necrosis in granulomatous lesions, indicating that NSE is produced by CD68-positive macrophages within granulomatous lesions (Fig. 3).

\section{Signals of NSE and CD68 in immunofluorescence analysis}

NSE and CD68 were examined in patient tissue microarrays containing normal lung, lung cancer, TB-infected, and necrotic TB-infected tissues. Staining of both NSE and CD68 was notably higher in TB tissues with nascent and necrotic lesions than in normal tissue (Fig. 4). Immunofluorescence analysis showed that both NSE and CD68 staining were strong at the cores of granulomas in both nascent and necrotic granulomatous lung tissues. Double staining of NSE and CD68 showed that NSE co-localized with CD68 in nascent and necrotic granulomas (Figs. 5 and 6). Information on the integrated den- 

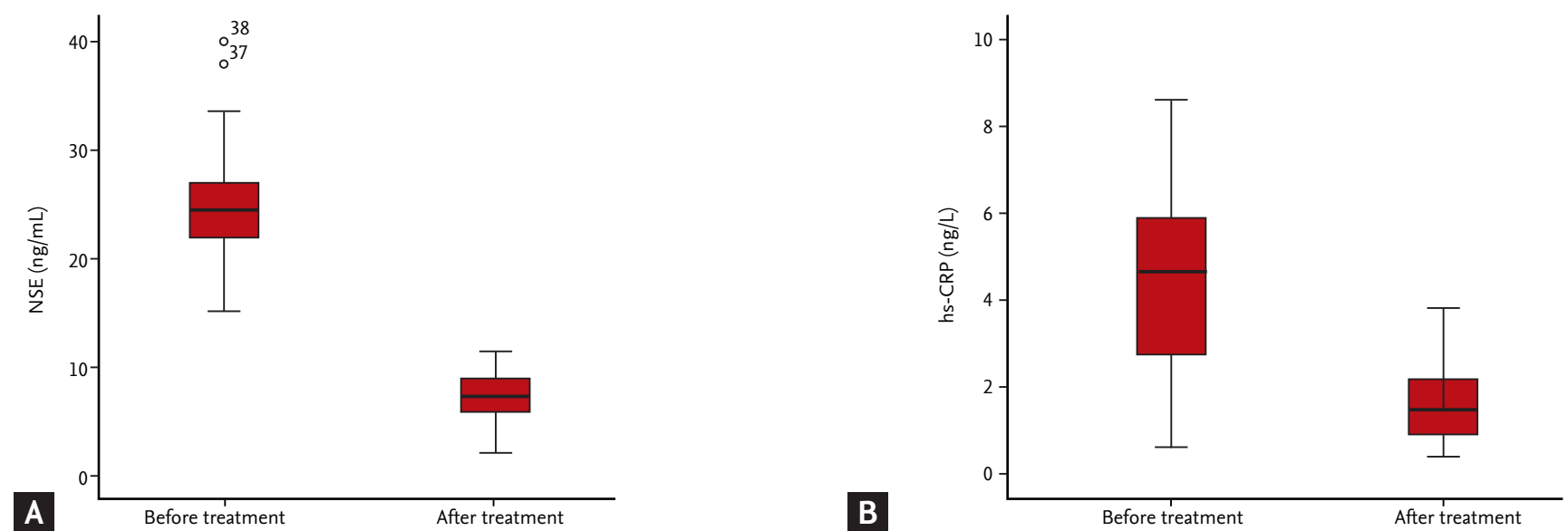

Figure 2. Changes in serum concentrations of(A) neuron-specific enolase (NSE) and (B) high-sensitivity C-reactive protein (hsCRP) after tuberculosis treatment.

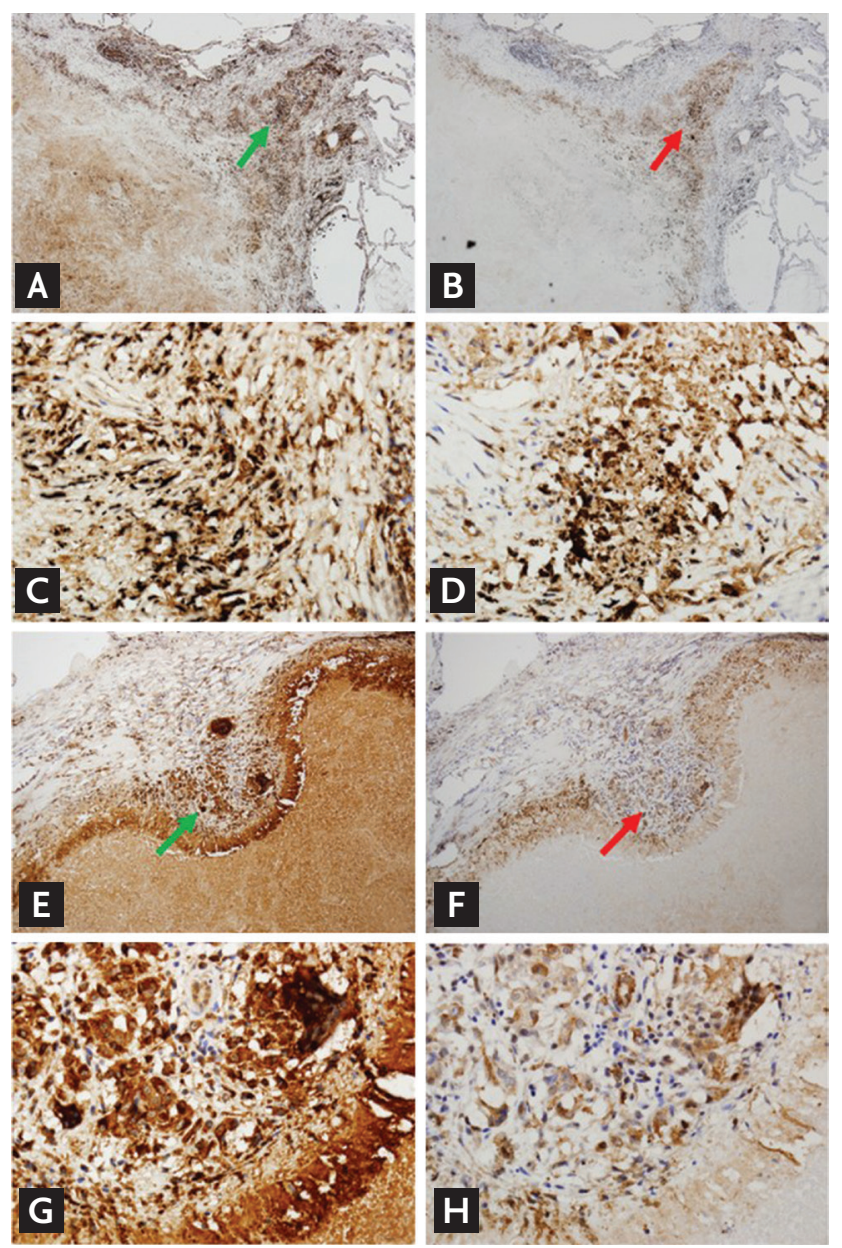

Figure 3. Detection of neuron-specific enolase (NSE)- and CD68-positive macrophages within granulomatous lesions. Immunohistochemical staining revealed a large number of NSE- (green arrows) and tissue macrophage cell marker CD68-positive macrophages (red arrows) around caseating necrosis in granulomatous lesions (A, C, E, G: NSE; B, D, F, H: CD68) (A, B, E, F: ×40; C, D, G, H: ×400). sity values of CD68 and NSE staining from immunofluorescence analysis of the tissue microarray are described in Supplementary Table 2.

\section{DISCUSSION}

Chest radiography, sputum acid-fast staining, and mycobacterial cultures are usually used for evaluating the therapeutic response of pulmonary TB [20]. However, these tests all have limitations. Chest radiography improves slowly with treatment and does not accurately reflect the activity of pulmonary TB. Acid-fast smear has poor sensitivity, requiring a large number of bacilli to be present in specimens [21]. Mycobacterial culture after treatment requires clinicians to wait up to several weeks, which delays response to treatment failure [22]. Thus, there is great need to discover novel clinical parameters that can quickly and accurately assess disease activity and/or treatment response.

Serum NSE concentration is a known useful biomarker of SCLC, retinoblastoma, and neuroblastoma [9,10]. Despite its clinical utility as a biomarker of malignant disease, NSE concentration has not been used to measure disease activity in TB patients. In our study, all TB patients showed elevated serum NSE concentration. More importantly, serum NSE and hs-CRP concentrations correlated with the extent of inflammation determined by chest X-ray (CXR). Patients with extensive-type infiltration had higher NSE and hs-CRP levels than those with focal segmental infiltration. In line with 

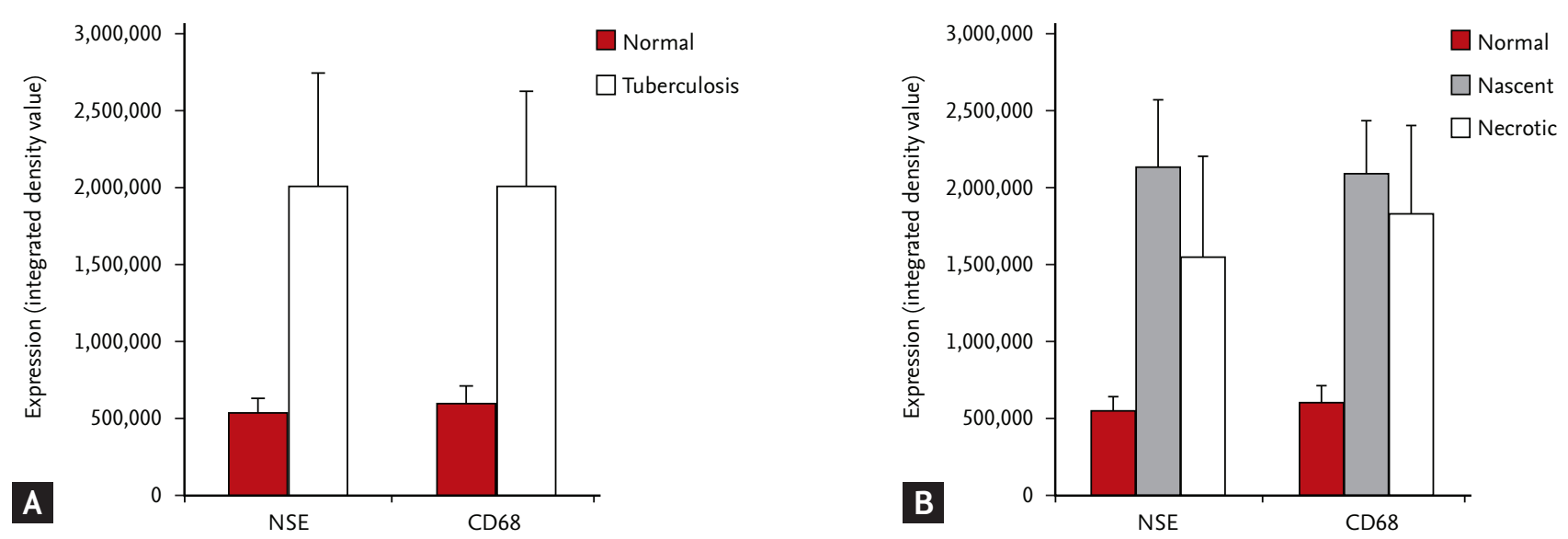

Figure 4. Immunofluorescence analysis of lung tissue microarrays consisting of 100 cores (80 tuberculosis-infected, eight lung cancer, and 12 normal). (A) Neuron-specific enolase (NSE) and tissue macrophage cell marker CD68 in normal and tuberculosis lung cores. NSE and CD68 signals were higher in tuberculosis cores than in normal cores. (B) Signals of NSE and CD68 in normal, nascent, and necrotic tuberculosis cores. NSE and CD68 signals were significantly increased in tuberculosis tissues containing nascent and necrotic cores.
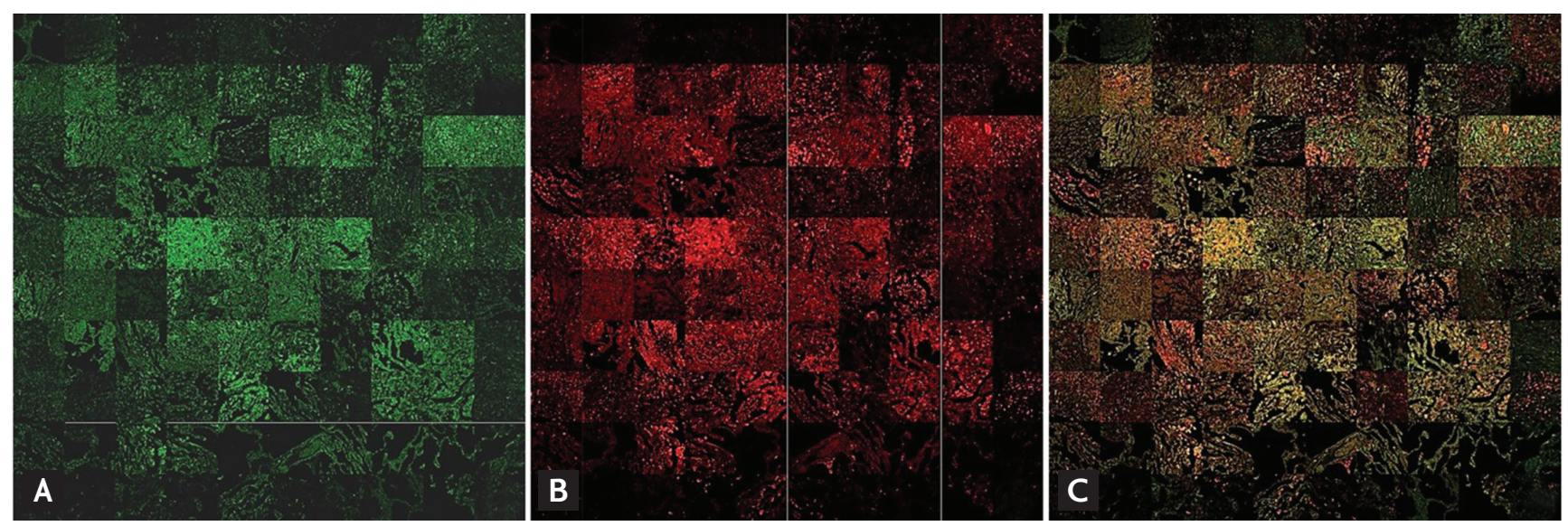

Figure 5. (A) Signals of neuron-specific enolase (NSE), (B) signals of tissue macrophage cell marker CD68, and (C) merged signals in immunofluorescence analysis of lung tissue microarrays consisting of 100 (80 tuberculosis-infected, eight lung cancer, and 12 normal) cores. NSE and CD68 signals are high in active pulmonary tuberculosis cores.

our observations, Collazos et al. [12] also reported that patients with alveolar infiltrates or interstitial patterns on CXR have higher NSE concentration than those with normal radiographs.

A hs-CRP, which is produced by the liver, is an acute phase protein that is often used as a nonspecific marker of benign inflammatory diseases and promotion of phagocytosis [23-25]. Thus, we also investigated the correlation between NSE and hs-CRP concentrations in pulmonary TB patient groups. We found a strong positive correlation between these parameters and observed that both NSE and hs-CRP concentrations decreased significantly after TB treatment (Fig. 2). Therefore, our results suggest that NSE in combination with hs-CRP may be a useful clinical parameter to test for pulmonary TB. Further investigation designed to determine the trends of NSE and hs-CRP during and at the end of TB treatment will be needed in order to develop NSE/hsCRP as biomarkers for treatment response monitoring. Almost all patient symptoms, radiological findings, and sputum AFB stains improved over the course of treatment in this study; however, we were unable to perform statistical analysis due to the small sample size.

While the incidence rate of TB continues to decline in most industrialized nations, patients with latent or multidrug-resistant TB infection still constitute a vast pool 

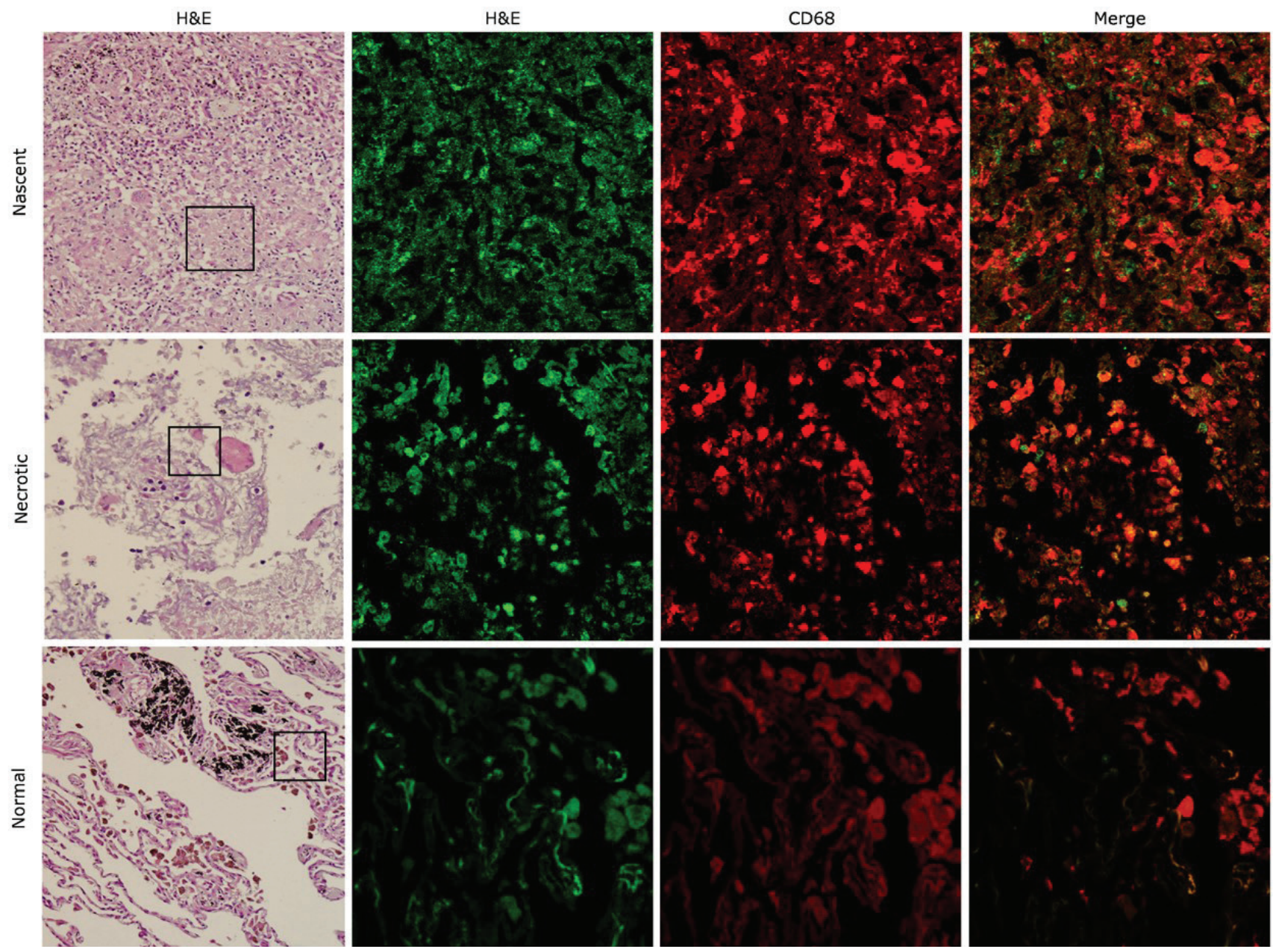

Figure 6. Signals and co-localization of neuron-specific enolase (NSE) and tissue macrophages cell marker CD68 in nascent (upper panels), necrotic granulomatous lung cores with active pulmonary tuberculosis (middle panels), and normal controls (lower panels). NSE was strongly detected around granulomas and co-localized with CD68. Magnification was $\times 200$ for H\&E staining and $\times 400$ for immunofluorescence.

of individuals who might develop TB, particularly when they become immunocompromised. The diagnosis and treatment of latent TB infection are therefore increasingly important goals for TB control $[26,27]$. Further research should be performed to confirm the relationship between NSE concentration and disease activity in latent T'B patients.

To our knowledge, there has been no concerted effort to understand the role of NSE in TB. In a study by Collazos et al. [12], the origin of NSE production was suggested to be destruction of neural and neuroendocrine cells. However, the exact origin of NSE has not been established in TB infection. In this study, we hypothesized that the origin of NSE is macrophages, which play a key role in the formation of granulomatous lesions in patients with active tuberculoma. Immunohistochemical staining revealed a large number of both NSE- and CD68-positive macrophages around caseating necrosis in granulomatous lesions. Immunofluorescence analysis showed that both NSE and CD68 signals were markedly higher and co-localized in the cores of granulomas in both nascent and necrotic granulomatous lung tissues compared to normal lung tissues. Based on these results, the elevated concentration of serum NSE in patients with granulomatous lesions might have originated from macrophages. Our study suggests the potential role of macrophages in elevated NSE concentrations in other benign lung diseases. The results obtained from this research should be further strengthened by the investigation of NSE and hs-CRP concentrations in other in- 
flammatory lung diseases, such as bacterial pneumonia.

In conclusion, Serum NSE and hs-CRP concentrations were elevated corresponding to the extent of lung inflammation in active pulmonary TB patients. With anti-TB treatment, NSE and hs-CRP concentrations decreased significantly with serial improvement in follow-up chest radiographs. Serum NSE and hs-CRP concentrations were related to the activity and severity of pulmonary TB. Further investigation is needed to identify NSE and hs-CRP as clinical parameters to monitor TB activity and treatment responses. Our results also suggest that elevated serum NSE concentration at least partially originates from macrophages in granulomatous lesions.

\section{KEY MESSAGE}

1. Serum neuron-specific enolase (NSE) and high-sensitivity C-reactive protein (hs-CRP) concentrations were related to the activity and severity of pulmonary tuberculosis (TB).

2. With anti-TB treatment, NSE and hs-CRP concentrations decreased significantly with serial improvement in follow-up chest radiographs.

3. Elevated serum NSE, at least, partially originates from macrophages in granulomatous lesions.

\section{Conflict of interest}

No potential conflict of interest relevant to this article was reported.

\section{Acknowledgments}

This research was supported in part by a grant from the Marine Biotechnology Program (No. 20150220) funded by the Ministry of Oceans and Fisheries, Korea (to $\mathrm{CHO}$ ), and also by Korea National Research Foundation (KNRF) grants 2014R1A1A2059665 funded by the Ministry of Education (to $\mathrm{CHO}$ ) and $2014 \mathrm{M}_{3} \mathrm{C}_{1} \mathrm{~A}_{3} 051981$ funded by the Ministry of Science, ICT \& Future Planning (to JYJ and HJC). The funders had no role in study design, data collection, interpretation, or decision to submit the work for publication.

\section{REFERENCES}

1. Lima MM, Trindade A, Carnavalli F, Bolognesi Melchior AC, Chin CM, Dos Santos JL. Tuberculosis: challenges to improve the treatment. Curr Clin Pharmacol 2015;10:242251.

2. The Lancet Infectious Diseases. The deadly synergy of HIV and tuberculosis. Lancet Infect Dis 2010;10:441.

3. Sunnetcioglu A, Sunnetcioglu M, Binici I, Baran AI, Karahocagil MK, Saydan MR. Comparative analysis of pulmonary and extrapulmonary tuberculosis of 411 cases. Ann Clin Microbiol Antimicrob 2015;14:34.

4. Westaway MS. Useful symptom complexes in the detection of tuberculosis. S Afr Med J 1992;81:432.

5. American Thoracic Society. Diagnostic standards and classification of tuberculosis. Am Rev Respir Dis 1990;142:725735 .

6. Bua A, Molicotti P, Delogu G, et al. QuantiFERON TB Gold: a new method for latent tuberculosis infection. New Microbiol 2007;30:477-480.

7. Pai M, Joshi R, Bandyopadhyay M, et al. Sensitivity of a whole-blood interferon-gamma assay among patients with pulmonary tuberculosis and variations in T-cell responses during anti-tuberculosis treatment. Infection 2007;35:98-103.

8. Johnson JL, Geldenhuys H, Thiel BA, et al. Effect of isoniazid therapy for latent TB infection on QuantiFERON-TB gold in-tube responses in adults with positive tuberculin skin test results in a high TB incidence area: a controlled study. Chest 2014;145:612-617.

9. Kuralay F, Tokgoz Z, Comlekci A. Diagnostic usefulness of tumour marker levels in pleural effusions of malignant and benign origin. Clin Chim Acta 2000;300:43-55.

10. Li CS, Cheng BC, Ge W, Gao JF. Clinical value of CYFRA21-1, NSE, CA15-3, CA19-9 and CA125 assay in the elderly patients with pleural effusions. Int J Clin Pract 2007;61:444-448.

11. Inoue S, Takahashi $\mathrm{H}$, Kaneko K. The fluctuations of neuron-specific enolase (NSE) levels of cerebrospinal fluid during bacterial meningitis: the relationship between the fluctuations of NSE levels and neurological complications or outcome. Acta Paediatr Jpn 1994;36:485-488.

12. Collazos J, Esteban C, Fernandez A, Genolla J. Measurement of the serum tumor marker neuron-specific enolase in patients with benign pulmonary diseases. Am J Respir Crit Care Med 1994;150:143-145. 
13. Song TJ, Choi YC, Lee KY, Kim WJ. Serum and cerebrospinal fluid neuron-specific enolase for diagnosis of tuberculous meningitis. Yonsei Med J 2012;53:1068-1072.

14. Stammet P, Collignon O, Hassager C, et al. Neuron-specific enolase as a predictor of death or poor neurological outcome after out-of-hospital cardiac arrest and targeted temperature management at $33^{\circ} \mathrm{C}$ and $36^{\circ} \mathrm{C}$. J Am Coll Cardiol 2015;65:2104-2114.

15. Choi CM, Kang CI, Jeung WK, Kim DH, Lee CH, Yim JJ. Role of the C-reactive protein for the diagnosis of TB among military personnel in South Korea. Int J Tuberc Lung Dis 2007;11:233-236.

16. Honda K, Ohga S, Takada H, et al. Neuron-specific enolase in hemophagocytic lymphohistiocytosis: a potential indicator for macrophage activation? Int J Hematol 2000;72:55-60.

17. Kang YJ, Jo JO, Ock MS, et al. Over-expression of thymosin beta 4 in granulomatous lung tissue with active pulmonary tuberculosis. Tuberculosis (Edinb) 2014;94:323-331.

18. Heitmann L, Abad Dar M, Schreiber T, et al. The IL-13/IL${ }_{4} \mathrm{R} \alpha$ axis is involved in tuberculosis-associated pathology. J Pathol 2014;234:338-350.

19. Lugo-Villarino G, Neyrolles O. Of clots and granulomas: platelets are new players in immunity to tuberculosis. J Infect Dis 2014;210:1687-1690.

20. Blumberg HM, Burman WJ, Chaisson RE, et al. American
Thoracic Society/Centers for Disease Control and Prevention/Infectious Diseases Society of America: treatment of tuberculosis. Am J Respir Crit Care Med 2003;167:603662.

21. Cheng VC, Yam WC, Hung IF, et al. Clinical evaluation of the polymerase chain reaction for the rapid diagnosis of tuberculosis. J Clin Pathol 2004;57:281-285.

22. Heo EY, Chun EJ, Lee CH, et al. Radiographic improvement and its predictors in patients with pulmonary tuberculosis. Int J Infect Dis 2009;13:e371-376.

23. Kang YA, Kwon SY, Yoon HI, Lee JH, Lee CT. Role of C-reactive protein and procalcitonin in differentiation of tuberculosis from bacterial community acquired pneumonia. Korean J Intern Med 2009;24:337-342.

24. Koster MJ, Broekhuizen BD, Minnaard MC, et al. Diagnostic properties of C-reactive protein for detecting pneumonia in children. Respir Med 2013;107:1087-1093.

25. Bafadhel M, Clark TW, Reid C, et al. Procalcitonin and C-reactive protein in hospitalized adult patients with community-acquired pneumonia or exacerbation of asthma or COPD. Chest 2011;139:1410-1418.

26. Whalen CC. Diagnosis of latent tuberculosis infection: measure for measure. JAMA 2005;293:2785-2787.

27. Jasmer RM, Nahid P, Hopewell PC. Clinical practice: latent tuberculosis infection. N Engl J Med 2002;347:18601866. 
Supplementary Table 1. Patient information of the lung tissue microarray used in this study

\begin{tabular}{|c|c|c|c|c|}
\hline No. & Sex & Age, yr & Organ & Pathology diagnosis \\
\hline 1 & M & 48 & Lung & Tuberculosis \\
\hline 2 & M & 48 & Lung & Tuberculosis \\
\hline 3 & M & 33 & Lung & Tuberculosis \\
\hline 4 & M & 33 & Lung & Tuberculosis \\
\hline 5 & M & 35 & Lung & $\begin{array}{l}\text { Tuberculosis (degenerative and } \\
\text { necrotic tissue) }\end{array}$ \\
\hline 6 & M & 35 & Lung & $\begin{array}{l}\text { Tuberculosis (degenerative and } \\
\text { necrotic tissue) }\end{array}$ \\
\hline 7 & F & 48 & Lung & Tuberculosis \\
\hline 8 & $\mathrm{~F}$ & 48 & Lung & Tuberculosis \\
\hline 9 & F & 46 & Lung & Tuberculosis \\
\hline 10 & F & 46 & Lung & Tuberculosis \\
\hline 11 & F & 66 & Lung & Tuberculosis \\
\hline 12 & $\mathrm{~F}$ & 66 & Lung & Tuberculosis \\
\hline 13 & $\mathrm{M}$ & 54 & Lung & Tuberculosis \\
\hline 14 & M & 54 & Lung & Tuberculosis \\
\hline 15 & $\mathrm{M}$ & 48 & Lung & Tuberculosis (sparse) \\
\hline 16 & $\mathrm{M}$ & 48 & Lung & Tuberculosis \\
\hline 17 & $\mathrm{M}$ & 63 & Lung & Tuberculosis \\
\hline 18 & M & 63 & Lung & Tuberculosis \\
\hline 19 & M & 63 & Lung & Tuberculosis \\
\hline 20 & M & 63 & Lung & Tuberculosis \\
\hline 21 & $\mathrm{~F}$ & 57 & Lung & Tuberculosis \\
\hline 22 & F & 57 & Lung & Tuberculosis \\
\hline 23 & F & 41 & Lung & Tuberculosis \\
\hline 24 & F & 41 & Lung & Tuberculosis \\
\hline 25 & M & 63 & Lung & Tuberculosis \\
\hline 26 & M & 63 & Lung & Tuberculosis \\
\hline 27 & F & 50 & Lung & Tuberculosis \\
\hline 28 & F & 50 & Lung & Tuberculosis \\
\hline 29 & F & 61 & Lung & Tuberculosis \\
\hline 30 & F & 61 & Lung & Tuberculosis \\
\hline 31 & F & 51 & Lung & Tuberculosis \\
\hline 32 & $\mathrm{~F}$ & 51 & Lung & Tuberculosis \\
\hline 33 & M & 39 & Lung & Tuberculosis \\
\hline 34 & M & 39 & Lung & $\begin{array}{l}\text { Tuberculosis (exudative } \\
\text { inflammation of tuberculosis) }\end{array}$ \\
\hline 35 & $\mathrm{~F}$ & 60 & Lung & Tuberculosis \\
\hline 36 & $\mathrm{~F}$ & 60 & Lung & Tuberculosis \\
\hline 37 & F & 61 & Lung & Tuberculosis \\
\hline 38 & $\mathrm{~F}$ & 61 & Lung & Tuberculosis \\
\hline 39 & M & 46 & Lung & Tuberculosis (necrotic tissue) \\
\hline 40 & M & 46 & Lung & Tuberculosis (necrotic tissue) \\
\hline 41 & M & 45 & Lung & Tuberculosis \\
\hline
\end{tabular}

\begin{tabular}{|c|c|c|c|c|}
\hline No. & Sex & Age, yr & Organ & Pathology diagnosis \\
\hline 42 & $\mathrm{M}$ & 45 & Lung & Tuberculosis \\
\hline 43 & M & 57 & Lung & Tuberculosis \\
\hline 44 & M & 57 & Lung & Tuberculosis \\
\hline 45 & $\mathrm{~F}$ & 55 & Lung & Tuberculosis \\
\hline 46 & $\mathrm{~F}$ & 55 & Lung & Tuberculosis \\
\hline 47 & M & 48 & Lung & Tuberculosis \\
\hline 48 & M & 48 & Lung & Tuberculosis \\
\hline 49 & M & 60 & Lung & Tuberculosis \\
\hline 50 & M & 60 & Lung & Tuberculosis \\
\hline 51 & M & 59 & Lung & Tuberculosis \\
\hline 52 & M & 59 & Lung & Tuberculosis \\
\hline 53 & M & 68 & Lung & Tuberculosis (necrotic tissue) \\
\hline 54 & M & 68 & Lung & Tuberculosis \\
\hline 55 & F & 38 & Lung & Tuberculosis \\
\hline 56 & F & 38 & Lung & Tuberculosis \\
\hline 57 & M & 75 & Lung & $\begin{array}{l}\text { Tuberculosis (sparse) with } \\
\text { necrosis }\end{array}$ \\
\hline 58 & M & 75 & Lung & $\begin{array}{l}\text { Tuberculosis (sparse) with } \\
\text { necrosis }\end{array}$ \\
\hline 59 & M & 49 & Lung & Tuberculosis \\
\hline 60 & M & 49 & Lung & Tuberculosis \\
\hline 61 & M & 45 & Lung & Tuberculosis \\
\hline 62 & M & 45 & Lung & Tuberculosis \\
\hline 63 & $\mathrm{~F}$ & 51 & Lung & Tuberculosis \\
\hline 64 & $\mathrm{~F}$ & 51 & Lung & $\begin{array}{l}\text { Tuberculosis with caseous } \\
\text { necrosis }\end{array}$ \\
\hline 65 & M & 43 & Lung & Tuberculosis \\
\hline 66 & M & 43 & Lung & Tuberculosis \\
\hline 67 & M & 40 & Lung & Tuberculosis (sparse) \\
\hline 68 & M & 40 & Lung & $\begin{array}{l}\text { Tuberculosis (exudative } \\
\text { inflammation of tuberculosis) }\end{array}$ \\
\hline 69 & M & 68 & Lung & Tuberculosis \\
\hline 70 & M & 68 & Lung & Tuberculosis \\
\hline 71 & M & 56 & Lung & Tuberculosis with necrosis \\
\hline 72 & M & 56 & Lung & Tuberculosis \\
\hline 73 & M & 51 & Lung & Tuberculosis \\
\hline 74 & M & 51 & Lung & Tuberculosis \\
\hline 75 & M & 60 & Lung & $\begin{array}{l}\text { Tuberculosis (mild exudative } \\
\text { inflammation of tuberculosis) }\end{array}$ \\
\hline 76 & M & 60 & Lung & $\begin{array}{l}\text { Tuberculosis (mild exudative } \\
\text { inflammation of tuberculosis) }\end{array}$ \\
\hline 77 & $\mathrm{~F}$ & 75 & Lung & Tuberculosis \\
\hline 78 & $\mathrm{~F}$ & 75 & Lung & Tuberculosis \\
\hline 79 & $\mathrm{~F}$ & 60 & Lung & Tuberculosis \\
\hline 80 & $\mathrm{~F}$ & 60 & Lung & Tuberculosis \\
\hline
\end{tabular}




\section{Supplementary Table 1. Continued}

\begin{tabular}{|c|c|c|c|c|}
\hline No. & Sex & Age, yr & Organ & Pathology diagnosis \\
\hline 81 & $\mathrm{~F}$ & 53 & Lung & $\begin{array}{l}\text { Cancer adjacent normal } \\
\text { pneumonic tissue }\end{array}$ \\
\hline 82 & $\mathrm{~F}$ & 53 & Lung & $\begin{array}{l}\text { Cancer adjacent normal } \\
\text { pneumonic tissue }\end{array}$ \\
\hline 83 & M & 67 & Lung & $\begin{array}{l}\text { Cancer adjacent normal } \\
\text { pneumonic tissue }\end{array}$ \\
\hline 84 & M & 67 & Lung & $\begin{array}{l}\text { Cancer adjacent normal } \\
\text { pneumonic tissue }\end{array}$ \\
\hline 85 & $\mathrm{~F}$ & 48 & Lung & $\begin{array}{l}\text { Cancer adjacent normal } \\
\text { pneumonic tissue (with local } \\
\text { chronic inflammation of } \\
\text { mesenchyma) of No.o7 }\end{array}$ \\
\hline 86 & $\mathrm{~F}$ & 48 & Lung & $\begin{array}{l}\text { Cancer adjacent normal } \\
\text { pneumonic tissue (mild } \\
\text { exudative inflammation) } \\
\text { of No.07 }\end{array}$ \\
\hline 87 & M & 48 & Lung & $\begin{array}{l}\text { Cancer adjacent normal } \\
\text { pneumonic tissue (mild } \\
\text { exudative inflammation) } \\
\text { of No.15 }\end{array}$ \\
\hline 88 & M & 48 & Lung & $\begin{array}{l}\text { Cancer adjacent normal } \\
\text { pneumonic tissue (mild } \\
\text { exudative inflammation) } \\
\text { of No.15 }\end{array}$ \\
\hline 89 & M & 48 & Lung & Normal pneumonic tissue \\
\hline 90 & $\mathrm{M}$ & 48 & Lung & Normal pneumonic tissue \\
\hline 91 & M & 19 & Lung & Normal pneumonic tissue \\
\hline 92 & M & 19 & Lung & Normal pneumonic tissue \\
\hline 93 & $\mathrm{M}$ & 25 & Lung & Normal pneumonic tissue \\
\hline 94 & $\mathrm{M}$ & 25 & Lung & Normal pneumonic tissue \\
\hline 95 & $\mathrm{M}$ & 49 & Lung & $\begin{array}{l}\text { Normal pneumonic with } \\
\text { bronchi tissue }\end{array}$ \\
\hline 96 & M & 49 & Lung & Normal pneumonic tissue \\
\hline 97 & $\mathrm{M}$ & 24 & Lung & Normal pneumonic tissue \\
\hline 98 & M & 24 & Lung & Normal pneumonic tissue \\
\hline 99 & $\mathrm{M}$ & 55 & Lung & Normal pneumonic tissue \\
\hline 100 & $\mathrm{M}$ & 55 & Lung & Normal pneumonic tissue \\
\hline
\end{tabular}


Supplementary Table 2. Signal intensities of NSE and CD68 from immunofluorescence analysis of the lung tissue microarray

\begin{tabular}{|c|c|c|c|c|c|c|c|c|c|c|c|}
\hline & IDV & $\begin{array}{c}\text { Percentage, } \\
\%^{\mathrm{a}}\end{array}$ & Area & $\begin{array}{l}\text { Aver- } \\
\text { age }\end{array}$ & $\begin{array}{l}\text { Back- } \\
\text { ground }\end{array}$ & & IDV & $\begin{array}{c}\text { Percentage, } \\
\%^{\mathrm{a}}\end{array}$ & Area & $\begin{array}{l}\text { Aver- } \\
\text { age }\end{array}$ & $\begin{array}{l}\text { Back- } \\
\text { ground }\end{array}$ \\
\hline NSE & & & & & & $42 n$ & $3,571,188$ & 2.1 & 257,013 & 14 & o \\
\hline 1n & 289,390 & 0.2 & 257,013 & 1 & 0 & $43 n$ & $2,987,711$ & 1.7 & 257,013 & 12 & o \\
\hline $2 \mathrm{n}$ & 528,332 & 0.3 & 257,013 & 2 & o & $44 \mathrm{n}$ & $9,301,566$ & $5 \cdot 4$ & 257,013 & 36 & 0 \\
\hline $3 n$ & 191,960 & 0.1 & 257,013 & 1 & o & $45 n$ & $4,425,785$ & 2.6 & 257,013 & 17 & o \\
\hline $4 \mathrm{n}$ & 233,109 & 0.1 & 257,013 & 1 & o & $46 n$ & $4,290,017$ & 2.5 & 257,013 & 17 & o \\
\hline $5^{n}$ & 460,667 & 0.3 & 257,013 & 2 & 0 & $47 n$ & $6,180,615$ & 3.6 & 257,013 & 24 & 0 \\
\hline $6 n$ & 287,986 & 0.2 & 257,013 & 1 & o & $48 n$ & $1,415,700$ & 0.8 & 257,013 & 6 & o \\
\hline $7 n$ & 62,885 & 0 & 257,013 & o & o & $49 n$ & $2,371,584$ & 1.4 & 257,013 & 9 & 0 \\
\hline $8 n$ & 277,562 & 0.2 & 257,013 & 1 & o & $50 n$ & $1,347,886$ & 0.8 & 257,013 & 5 & o \\
\hline 9n & $1,778,598$ & 1 & 257,013 & 7 & o & $51 n$ & $2,306,523$ & 1.3 & 257,013 & 9 & o \\
\hline 10n & 740,833 & 0.4 & 257,013 & 3 & o & $52 \mathrm{n}$ & $1,895,044$ & 1.1 & 257,013 & 7 & o \\
\hline $11 n$ & $1,731,046$ & 1 & 257,013 & 7 & O & $53 n$ & 478,427 & 0.3 & 257,013 & 2 & o \\
\hline $12 \mathrm{n}$ & $3,370,721$ & 2 & 257,013 & 13 & o & $54 \mathrm{n}$ & $2,537,642$ & 1.5 & 257,013 & 10 & o \\
\hline $13 n$ & $1,670,95^{8}$ & 1 & 257,013 & 7 & o & $55 n$ & $2,440,400$ & 1.4 & 257,013 & 9 & o \\
\hline $14 n$ & $1,448,048$ & 0.8 & 257,013 & 6 & o & $56 n$ & $3,337,054$ & 2 & 257,013 & 13 & o \\
\hline $15 n$ & $2,302,506$ & 1.3 & 257,013 & 9 & 0 & $57 n$ & $1,177,716$ & 0.7 & 257,013 & 5 & o \\
\hline $16 n$ & $1,237,756$ & 0.7 & 257,013 & 5 & o & $58 n$ & $1,479,189$ & 0.9 & 257,013 & 6 & o \\
\hline $17 n$ & $2,280,311$ & 1.3 & 257,013 & 9 & 0 & $59 n$ & 643,524 & 0.4 & 257,013 & 3 & 0 \\
\hline $18 n$ & $1,605,987$ & 0.9 & 257,013 & 6 & o & 6on & 465,200 & 0.3 & 257,013 & 2 & o \\
\hline $19 n$ & 582,166 & 0.3 & 257,013 & 2 & 0 & $61 n$ & 764,269 & 0.4 & 257,013 & 3 & 0 \\
\hline $20 n$ & 716,241 & 0.4 & 257,013 & 3 & o & $62 n$ & $1,870,285$ & 1.1 & 257,013 & 7 & o \\
\hline $21 n$ & 898,941 & 0.5 & 257,013 & 3 & o & $63 n$ & $1,554,462$ & 0.9 & 257,013 & 6 & 0 \\
\hline $22 n$ & $3,119,361$ & 1.8 & 257,013 & 12 & o & $64 n$ & $2,734,037$ & 1.6 & 257,013 & 11 & o \\
\hline $23 n$ & $2,276,551$ & 1.3 & 257013 & 9 & 0 & $65 n$ & $3,939,395$ & 2.3 & 257,013 & 15 & o \\
\hline $24 n$ & $3,293,353$ & 1.9 & 257,013 & 13 & O & $66 n$ & $2,984,966$ & 1.7 & 257,013 & 12 & o \\
\hline $25 n$ & 919,081 & 0.5 & 257,013 & 4 & 0 & $67 n$ & 587,407 & 0.3 & 257,013 & 2 & 0 \\
\hline $26 n$ & $4,159,633$ & 2.4 & 257,013 & 16 & o & $68 n$ & $3,827,133$ & 2.2 & 257,013 & 15 & o \\
\hline $27 n$ & $4,394,070$ & 2.6 & 257,013 & 17 & o & $69 n$ & $3,186,392$ & 1.9 & 257,013 & 12 & o \\
\hline $28 n$ & $1,356,688$ & 0.8 & 257,013 & 5 & o & $70 n$ & 640,659 & 0.4 & 257,013 & 2 & o \\
\hline $29 n$ & $6,816,635$ & 4 & 257,013 & 27 & o & $71 n$ & 676,958 & 0.4 & 257,013 & 3 & 0 \\
\hline $30 n$ & $5,862,373$ & $3 \cdot 4$ & 257,013 & 23 & o & $72 n$ & 526,925 & 0.3 & 257,013 & 2 & o \\
\hline $31 n$ & 985,531 & 0.6 & 257,013 & 4 & 0 & $73 n$ & $1,230,976$ & 0.7 & 257,013 & 5 & o \\
\hline $32 n$ & 880,021 & 0.5 & 257,013 & 3 & o & $74 n$ & $1,197,358$ & 0.7 & 257,013 & 5 & O \\
\hline $33 n$ & $2,241,568$ & 1.3 & 257,013 & 9 & o & $75 n$ & $4,532,963$ & 2.7 & 257,013 & 18 & o \\
\hline $34 n$ & $1,518,495$ & 0.9 & 257,013 & 6 & o & $76 n$ & $1,094,212$ & 0.6 & 257,013 & 4 & o \\
\hline $35 n$ & $2,085,702$ & 1.2 & 257,013 & 8 & o & $77 n$ & 704,976 & 0.4 & 257,013 & 3 & o \\
\hline $36 n$ & 918,074 & 0.5 & 257,013 & 4 & o & $78 n$ & $3,106,983$ & 1.8 & 257,013 & 12 & o \\
\hline $37 n$ & $1,357,300$ & 0.8 & 257,013 & 5 & 0 & $79 n$ & $2,885,705$ & 1.7 & 257,013 & 11 & 0 \\
\hline $38 n$ & $1,293,726$ & 0.8 & 257,013 & 5 & o & 8on & 579,921 & 0.3 & 257,013 & 2 & o \\
\hline $39 n$ & $1,143,014$ & 0.7 & 257,013 & 4 & 0 & $81 n$ & 536,515 & 0.3 & 257,013 & 2 & 0 \\
\hline $40 n$ & 682,373 & 0.4 & 257,013 & 3 & o & $82 n$ & 350,529 & 0.2 & 257,013 & 1 & o \\
\hline $41 n$ & $1,132,523$ & 0.7 & 257,013 & 4 & 0 & $83 n$ & $1,883,078$ & 1.1 & 257,013 & 7 & 0 \\
\hline
\end{tabular}


Supplementary Table 2. Continued

\begin{tabular}{|c|c|c|c|c|c|c|c|c|c|c|c|}
\hline & IDV & $\begin{array}{c}\text { Percentage, } \\
\%^{\mathrm{a}}\end{array}$ & Area & $\begin{array}{l}\text { Aver- } \\
\text { age }\end{array}$ & $\begin{array}{l}\text { Back- } \\
\text { ground }\end{array}$ & & IDV & $\begin{array}{c}\text { Percentage, } \\
\%^{\mathrm{a}}\end{array}$ & Area & $\begin{array}{l}\text { Aver- } \\
\text { age }\end{array}$ & $\begin{array}{l}\text { Back- } \\
\text { ground }\end{array}$ \\
\hline $84 \mathrm{n}$ & $1,189,119$ & 0.7 & 257,013 & 5 & o & $25 n$ & 842,473 & 0.5 & 252,909 & 3 & 0 \\
\hline $85 n$ & 351,591 & 0.2 & 257,013 & 1 & 0 & $26 n$ & $4,438,663$ & 2.6 & 252,909 & 18 & 0 \\
\hline $86 n$ & 597,704 & 0.3 & 257,013 & 2 & 0 & $27 n$ & $2,819,689$ & 1.6 & 252,909 & 11 & o \\
\hline $87 n$ & $1,256,178$ & 0.7 & 257,013 & 5 & 0 & $28 n$ & $2,236,082$ & 1.3 & 252,909 & 9 & 0 \\
\hline $88 n$ & 647,212 & 0.4 & 257,013 & 3 & o & $29 n$ & $4,297,880$ & 2.5 & 252,909 & 17 & 0 \\
\hline $89 n$ & 679,439 & 0.4 & 257,013 & 3 & 0 & $30 n$ & $3,408,665$ & 2 & 252,909 & 13 & 0 \\
\hline $90 n$ & 626,299 & 0.4 & 257,013 & 2 & o & $31 n$ & $1,790,610$ & 1 & 252,909 & 7 & 0 \\
\hline $91 n$ & 89,269 & 0.1 & 257,013 & 0 & 0 & $32 n$ & $1,198,925$ & 0.7 & 252,909 & 5 & 0 \\
\hline $92 n$ & 60,288 & 0 & 257,013 & o & o & $33 n$ & $1,830,000$ & 1.1 & 252,909 & 7 & 0 \\
\hline $93 n$ & 350,349 & 0.2 & 257,013 & 1 & o & $34 n$ & $1,206,842$ & 0.7 & 252,909 & 5 & 0 \\
\hline $94 \mathrm{n}$ & 111,856 & 0.1 & 257,013 & o & o & $35 n$ & $2,148,506$ & 1.2 & 252,909 & 8 & 0 \\
\hline $95 n$ & 684,124 & 0.4 & 257,013 & 3 & o & $36 n$ & $1,286,946$ & 0.7 & 252,909 & 5 & 0 \\
\hline $96 n$ & 176,048 & 0.1 & 257,013 & 1 & 0 & $37 n$ & $1,329,067$ & 0.8 & 252,909 & 5 & 0 \\
\hline $97 n$ & 194,467 & 0.1 & 257,013 & 1 & o & $38 n$ & 792,885 & 0.5 & 252,909 & 3 & 0 \\
\hline $98 n$ & 276,262 & 0.2 & 257,013 & 1 & 0 & $39 n$ & $1,772,235$ & 1 & 252,909 & 7 & 0 \\
\hline $99 n$ & 336,814 & 0.2 & 257,013 & 1 & o & $40 n$ & 934,009 & 0.5 & 252,909 & 4 & 0 \\
\hline 10on & 160,489 & 0.1 & 257,013 & 1 & o & $41 n$ & $2,257,974$ & 1.3 & 252,909 & 9 & 0 \\
\hline CD68 & & & & & & $42 n$ & $5,885,393$ & $3 \cdot 4$ & 252,909 & 23 & 0 \\
\hline in & 272,621 & 0.2 & 252,909 & 1 & o & $43 n$ & $3,708,362$ & 2.1 & 252,909 & 15 & 0 \\
\hline $2 \mathrm{n}$ & 352,239 & 0.2 & 252,909 & 1 & o & $44 n$ & $8,024,035$ & $4 \cdot 6$ & 252,909 & 32 & 0 \\
\hline $3 n$ & 297,696 & 0.2 & 252,909 & 1 & o & $45 n$ & $2,995,090$ & 1.7 & 252,909 & 12 & 0 \\
\hline $4 \mathrm{n}$ & 298,099 & 0.2 & 252,909 & 1 & o & $46 n$ & $3,036,194$ & 1.8 & 252,909 & 12 & 0 \\
\hline $5 n$ & 331,632 & 0.2 & 252,909 & 1 & o & $47 n$ & $3,530,252$ & 2 & 252,909 & 14 & 0 \\
\hline $6 n$ & 479,061 & 0.3 & 252,909 & 2 & o & $48 n$ & $1,296,583$ & 0.8 & 252,909 & 5 & 0 \\
\hline $7 \mathrm{n}$ & 413,092 & 0.2 & 252,909 & 2 & o & $49 n$ & $1,590,917$ & 0.9 & 252,909 & 6 & 0 \\
\hline $8 n$ & 286,233 & 0.2 & 252,909 & 1 & o & $50 n$ & 703,308 & 0.4 & 252,909 & 3 & 0 \\
\hline on & 659,294 & 0.4 & 252,909 & 3 & o & $51 n$ & $1,584,921$ & 0.9 & 252,909 & 6 & 0 \\
\hline 10n & $1,210,446$ & 0.7 & 252,909 & 5 & 0 & $52 n$ & $2,370,691$ & 1.4 & 252,909 & 9 & 0 \\
\hline $11 n$ & $1,578,189$ & 0.9 & 252,909 & 6 & 0 & $53 n$ & $1,193,708$ & 0.7 & 252,909 & 5 & 0 \\
\hline $12 n$ & $4,157,119$ & 2.4 & 252,909 & 16 & 0 & $54 \mathrm{n}$ & $2,181,904$ & 1.3 & 252,909 & 9 & 0 \\
\hline $13 n$ & $1,474,054$ & 0.9 & 252,909 & 6 & 0 & $55^{n}$ & $2,789,296$ & 1.6 & 252,909 & 11 & 0 \\
\hline $14 \mathrm{n}$ & $2,309,394$ & 1.3 & 252,909 & 9 & o & $56 n$ & $3,252,925$ & 1.9 & 252,909 & 13 & 0 \\
\hline $15 n$ & $2,750,785$ & 1.6 & 252,909 & 11 & o & $57 n$ & $2,098,914$ & 1.2 & 252,909 & 8 & 0 \\
\hline $16 n$ & $2,397,878$ & 1.4 & 252,909 & 9 & o & $58 n$ & $2,712,999$ & 1.6 & 252,909 & 11 & 0 \\
\hline $17 n$ & $1,842,310$ & 1.1 & 252,909 & 7 & 0 & $59 n$ & 559,076 & 0.3 & 252,909 & 2 & o \\
\hline $18 n$ & $1,178,920$ & 0.7 & 252,909 & 5 & 0 & 6on & 444,888 & 0.3 & 252,909 & 2 & 0 \\
\hline $19 n$ & 998,922 & 0.6 & 252,909 & 4 & 0 & 6in & $1,206,509$ & 0.7 & 252,909 & 5 & 0 \\
\hline $20 n$ & 388,898 & 0.2 & 252,909 & 2 & 0 & $62 n$ & $1,733,087$ & 1 & 252,909 & 7 & 0 \\
\hline $21 n$ & 962,098 & 0.6 & 252,909 & 4 & 0 & $63 n$ & $4,210,400$ & 2.4 & 252,909 & 17 & 0 \\
\hline $22 n$ & $2,531,475$ & 1.5 & 252,909 & 10 & o & $64 n$ & $3,969,648$ & 2.3 & 252,909 & 16 & 0 \\
\hline $23 n$ & $3,136,515$ & 1.8 & 252,909 & 12 & 0 & $65 n$ & $3,394,936$ & 2 & 252,909 & 13 & 0 \\
\hline $24 n$ & $3,134,319$ & 1.8 & 252,909 & 12 & 0 & $66 n$ & $2,493,201$ & 1.4 & 252,909 & 10 & 0 \\
\hline
\end{tabular}


Nam SJ, et al. Usefulness of NSE in TB activity

Supplementary Table 2. Continued

\begin{tabular}{|c|c|c|c|c|c|}
\hline & IDV & $\begin{array}{c}\text { Percentage, } \\
\%^{\mathrm{a}}\end{array}$ & Area & $\begin{array}{l}\text { Aver- } \\
\text { age }\end{array}$ & $\begin{array}{l}\text { Back- } \\
\text { ground }\end{array}$ \\
\hline $67 n$ & 470,272 & 0.3 & 252,909 & 2 & o \\
\hline $68 n$ & $2,717,459$ & 1.6 & 252,909 & 11 & 0 \\
\hline 69n & $3,419,852$ & 2 & 252,909 & 14 & o \\
\hline 7on & 219,899 & 0.1 & 252,909 & 1 & 0 \\
\hline $71 n$ & $1,735,223$ & 1 & 252,909 & 7 & o \\
\hline $72 n$ & $1,145,693$ & 0.7 & 252,909 & 5 & 0 \\
\hline $73 n$ & $2,245,016$ & 1.3 & 252,909 & 9 & o \\
\hline $74 \mathrm{n}$ & $1,716,389$ & 1 & 252,909 & 7 & 0 \\
\hline $75 n$ & $3,554,535$ & 2.1 & 252,909 & 14 & 0 \\
\hline $76 n$ & $1,199,815$ & 0.7 & 252,909 & 5 & 0 \\
\hline $77 n$ & $1,171,464$ & 0.7 & 252,909 & 5 & 0 \\
\hline $78 \mathrm{n}$ & $2,624,528$ & 1.5 & 252,909 & 10 & 0 \\
\hline $79 n$ & $2,598,483$ & 1.5 & 252,909 & 10 & 0 \\
\hline 8 on & $1,158,304$ & 0.7 & 252,909 & 5 & 0 \\
\hline $81 n$ & 691,254 & 0.4 & 252,909 & 3 & o \\
\hline $82 n$ & 426,622 & 0.2 & 252,909 & 2 & 0 \\
\hline $83 n$ & $2,597,715$ & 1.5 & 252,909 & 10 & 0 \\
\hline $84 n$ & $1,342,238$ & 0.8 & 252,909 & 5 & 0 \\
\hline $85 n$ & 430,158 & 0.2 & 252,909 & 2 & o \\
\hline $86 n$ & 776,410 & 0.4 & 252,909 & 3 & 0 \\
\hline $87 n$ & 948,635 & 0.5 & 252,909 & 4 & o \\
\hline $88 n$ & 526,053 & 0.3 & 252,909 & 2 & 0 \\
\hline $89 n$ & 347,639 & 0.2 & 252,909 & 1 & 0 \\
\hline $90 \mathrm{n}$ & 94,294 & 0.1 & 252,909 & o & o \\
\hline 91n & 240,027 & 0.1 & 252,909 & 1 & o \\
\hline $92 n$ & 165,098 & 0.1 & 252,909 & 1 & 0 \\
\hline $93 n$ & 413,046 & 0.2 & 252,909 & 2 & 0 \\
\hline $94 n$ & 322,459 & 0.2 & 252,909 & 1 & o \\
\hline $95 n$ & 902,481 & 0.5 & 252,909 & 4 & o \\
\hline $96 n$ & 371,290 & 0.2 & 252,909 & 1 & 0 \\
\hline $97 n$ & 286,806 & 0.2 & 252,909 & 1 & 0 \\
\hline $98 n$ & 242,282 & 0.1 & 252,909 & 1 & o \\
\hline $99 n$ & 364,952 & 0.2 & 252,909 & 1 & 0 \\
\hline 10on & 96,157 & 0.1 & 252,909 & 0 & 0 \\
\hline
\end{tabular}

NSE, neuron-specific enolase; IDV, integrated density value.

${ }^{a}$ Based on standard IDV (black, o; white, 255). 